\title{
Coordination of SPS and CES to Mitigate Oscillatory Condition on Power Systems
}

\author{
Rahmat Septian Wijanarko ${ }^{* 1}$, Herlambang Setiadi ${ }^{2}$, Teguh Aryo Nugroho $^{3}$ \\ ${ }^{1,3}$ Departmen Teknik Elektro, Universitas Pertamina, Jl Teuku Nyak Arief, \\ Jakarta 12220, Indonesia \\ ${ }^{2}$ School of Information Technology \& Electrical Engineering, \\ The University of Queensland, St Lucia, Queensland 4072, Australia \\ *Corresponding author, e-mail: rahmat.sw@universitaspertamina.ac.id", h.setiadi@uq.edu.au², \\ teguh.an@universitaspertamina.ac.id ${ }^{3}$
}

\begin{abstract}
Oscillatory condition on power system (low-frequency oscillation) is one of the important factors to determine the quality of the power system. With the increasing number of load demand, this condition is getting worse in recent years. Hence, utilizing addition devices to maintain and mitigate the oscillatory condition of power system is crucial. This paper proposed a method to mitigate power system oscillation by installing one of the flexible AC transmission system (FACTS) devices called solid phase shifter (SPS) and energy storage devices called capacitor energy storage (CES). To analyze the performance of power system with SPS and CES, the eigenvalue and damping ratio analysis are used. Time domain simulation is also investigated to analyze the dynamic behaviors of power system considering SPS and CES. Furthermore, increasing number of load demand is carried out to analyze how much load can be increased without increasing power to the grid. From the simulation, it is found that SPS and CES can mitigate lowfrequency oscillation on power system indicated by highest damping, smallest overshoot, and fastest settling time. It is also found that load demand can be increased significantly when SPS and CES installed to the system.
\end{abstract}

Keywords: oscillatory condition, SPS, CES, eigenvalue, damping ratio

Copyright $\odot 2017$ Universitas Ahmad Dahlan. All rights reserved.

\section{Introduction}

Human population growth in the last few decades tends to increase significantly. With the population growth and development of technology, the electric power demand is increasing significantly as well. This increased electric load demand condition could effect the system instability. Oscillatory condition/small-signal stability is the stability class that can be effected by the increasing load demand. This oscillatory condition may be very troublesome if they are not damped. Kundur and .co in [1,2] have investigated that different modes of oscillatations was the cause of the blackouts in Canada on 1965, Brazil on 1999, India on July 2012 and Bangladesh on November 2014.

The ability of power system to maintain the stable condition in specific operating condition after being excited by perturbation is called small signal stability/oscillatory condition [3]. This condition has a frequency oscillation ranging from of $0.1-2 \mathrm{~Hz}$. Generally, the damper winding in the generator is one of the ways to handle this oscillatory condition. Another way is by installing PSS in the exciter of the generator [2]. The application of PSS to mitigate oscillatory condition has been investigated extensively in the last few decades [4-7]. However, PSS alone is not effective enough to overcome oscillatory condition because of significant increasing of load demand. Hence, additional devices such as storage devices and flexible AC transmission systems (FACTS) device can be a prominent alternative.

There are some energy storages which have been proposed in recent years such as redox flow battery and battery energy storage systems [8-12]. Another type is called superconducting magnetic and capacitor energy storage [13-16]. Among of storage system type, capacitor energy storage is becoming most favorable due to its fast response and large capacity. CES is generally uses as a frequency, voltage control, and peak load shaving. 
However, CES utilized as a small-signal stability enhancement have not been investigated, yet due to its capability, it can be one promising solution.

This paper proposed a novel solution using CES combined with one of FACTS devices called Solid Phase Shifter (SPS) to mitigate oscillatory condition in power system. By implementing this new method, damping value of the system was intended can be improved significantly and the increasing load demand in the system could be handled. The paper is organized as follow: Section 2 provides an overview of modelling the power system, CES, and SPS. This section also provides a brief explanation of oscillatory stability and how to analyze it. Time domain simulation and modal analysis are described in section 3. Section 4 focused on the contribution, conclusion and future direction for this research.

\section{Research Method}

\subsection{Dynamic model of power systems}

In oscillatory instability study, two different representation of power system can be investigated depending of the research interest. Single-machine infinite bus (SMIB) systems can be utilized if the interist only to capture dynamic behavior of local mode. In contrast, a complete multi-machine model can be utilized to capture local and inter-area (global) dynamic behaviors. In this research, the only local mode is investigated [17]. Hence, a simple model of power system called SMIB is used. Figure 1 illustrates the dynamic representation of SMIB $[18,19]$.

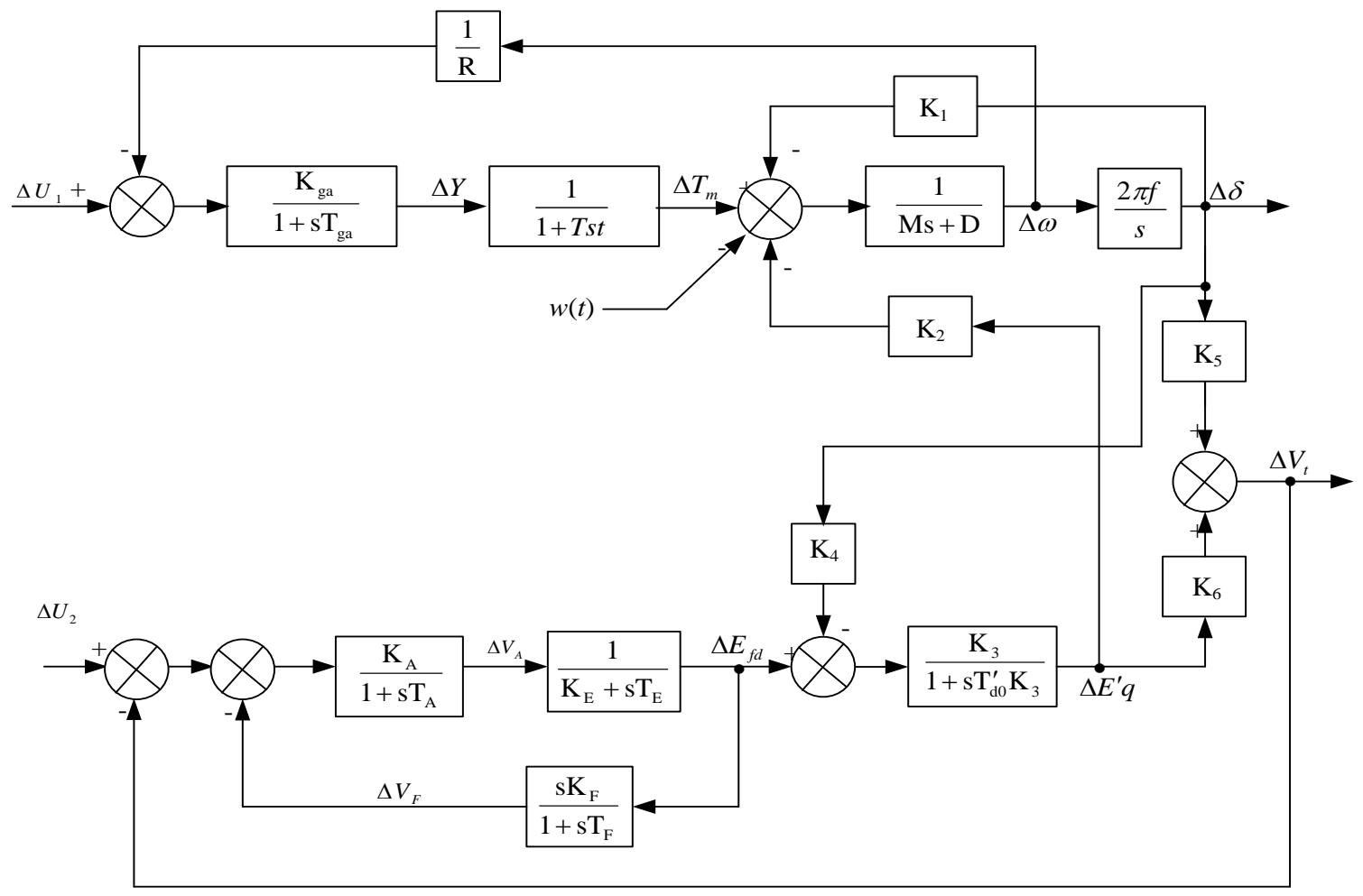

Figure 1. A dynamic representation of SIMB $[18,19]$

\subsection{Capacitor Energy Storage Model}

In last few decade, the application of energy storage increases significantly due to the development of power electronic devices. Capacitor energy storage (CES) is one type of storage systems that has become popular to handle frequency fluctuation on the power system. CES can store and release power to the grid instantionesly. For small signal stability application, dynamic characteristic of CES is crucial. The mathematical model of CES can be described using equation (1)-(3) [20-22]. 


$$
\begin{aligned}
& \Delta I_{d i} \frac{\left[K_{c e s} \Delta \omega-K_{v d} \Delta E_{d}\right]}{1+s T_{d c}} \\
& \Delta E_{d}\left[\frac{1}{s C+1 / R}\right] \Delta I_{d} \\
& \Delta P_{c e s}=\left(\Delta E_{d 0}+\Delta E_{d}\right) \Delta I_{d}
\end{aligned}
$$

Where $\Delta I_{d i}$ and $\Delta E_{d}$ are current deviation flowing through the capacitor and DC voltage applied to the capacitor. While $\Delta P_{\text {ces }}$ and $C$ are active power delivered to the grid and capacitance of the capacitors. Several parameters corresponding to resistance on the capacitors $(R)$, gain feedback $\left(K_{v d}\right)$, gain of the converter $\left(K_{c e s}\right)$, and time delay of the converter $\left(T_{d c}\right)$ [20-22]. From the equation (1)-(3), CES can be modeled into block diagram as shown in Figure 2.

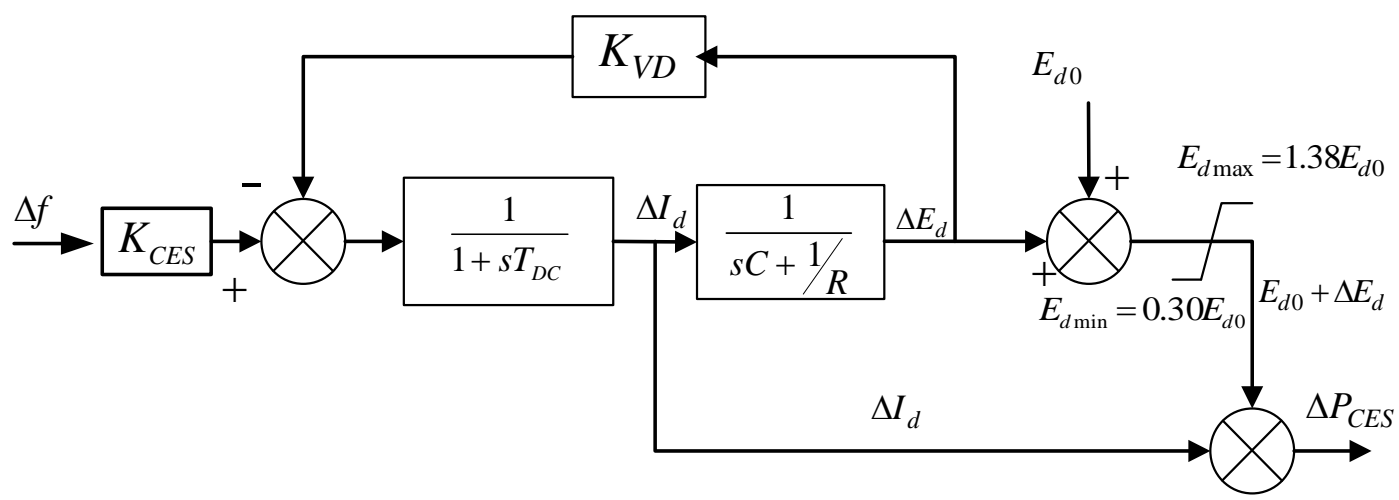

Figure 2. Block diagram of capacitor energy storage [20-22]

\subsection{Solid Phase Shifter Model}

The application of FACTS devices in power system has been increased significantly in recent years. FACTS can be used to control and maintaning, voltage, load flow, frequency as well as damping performance [23]. One of the FACTS devices type that become favorable as one of oscillation damping is solid state phase shifter (SPS). The purpose of SPS is to shift the voltage angle by reducing actual angle with angle come from SPS [24]. Hence, oscillatory condition can be mitigated by controlling the internal voltage and voltage angle of the power systems [24]. Figure 3 shows the representation of SPS for oscillatory instability [24].

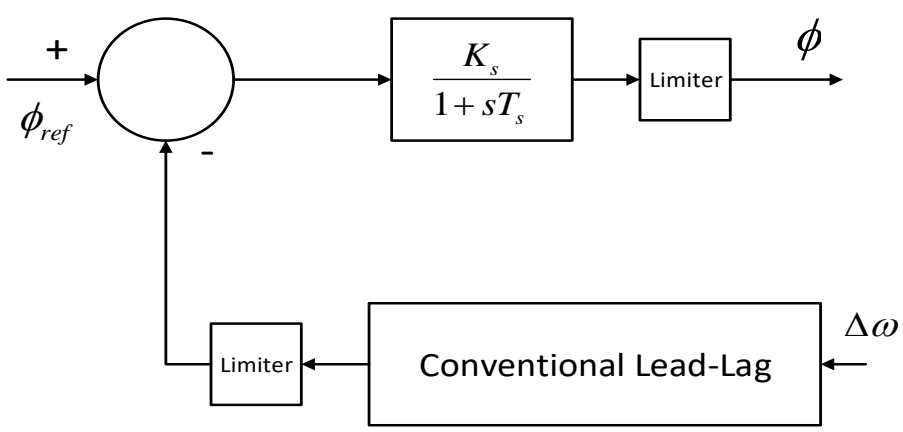

Figure 3. Block diagram of solid phase shifter [24]

\subsection{Oscillatory Condition on Power System}

Oscillatory condition on power system falls under small perturbation rotor angle stability $[25,26]$. Insufficient of synchronizing and lack of damping torques is the root cause of oscillatory 
instability. The magnitude of the oscillation could potentially growing until the system losses synchronization, If this instability is not properly handled [26,27]. This will cause the system blackout $[26,28]$.

The oscillatory condition can local and inter-area (global) problems. The local problems associated with local power plant again in one particular area. The frequency oscillation of local phenomena ussualy between 0.7 to $2 \mathrm{~Hz}$ [26,27]. Furthermore, Inter-area (global) phenomenon related to a large number of system again each other. As reported $[26,27]$ the frequency oscillation of inter-area mode is between 0.1 to $0.7 \mathrm{~Hz}$. Eigenvalue analysis is used to analyze the oscillatory condition of the power system. To determine the eigenvalue of the system, linearized of the system is crucial. Linearized of the investigated system can be represented as state space model investigated through (4) and (5) $[26,29]$. State variables, algebraic variables, input vector, plant matrix, control matrix, output matrix and feedfordward matrix are described as $\Delta x, \Delta y, \Delta u, A, B, C$ and $D[26,29]$. To determine the eigenvalue of the system matrix $A$ value is important. Equation (6) can be used to extract the eigenvalue from matrix $A[26,29]$.

$$
\begin{aligned}
& \Delta \dot{x}=A \Delta x+B \Delta u \\
& \Delta y=C \Delta x+D \Delta u \\
& \operatorname{det}(\lambda I-A)=0
\end{aligned}
$$

The identity matrix and eigenvalue are indicated by $I$ and $\lambda$. Moreover, mathematical representation of complex eigenvalue can be described as $(7)[26,30]$. Furthermore, frequency oscillation and damping performance of the system can be calculated using equation (8) and (9). Real and imaginary parts of eigenvalue can be denoted by $\left(\omega_{i}\right)$ and $\left(\sigma_{i}\right)[26,30]$.

$$
\begin{aligned}
& \lambda_{i}=\sigma_{i} \pm j \omega_{i} \\
& f_{i}=\frac{\omega_{i}}{2 \pi}(H z) \\
& \xi=\frac{\sigma_{i}}{\sqrt{\sigma_{i}^{2}+\omega_{i}^{2}}}
\end{aligned}
$$

\section{Numerical Results and Analysis}

For investigated the effeciecy of SPS and CES for mitigating oscillatory condition, two different case studies were reported in this work. MATLAB/SIMULINK environment was used to simulate all of the study cases in this paper. To investigate the impact of SPS and CES in oscillatory instability, the comparison of eigenvalue and damping performance of electromechanical mode (EM) were conducted. Furthermore, the increased load demand was conducted to understand how much load can be increased after installing SPS and CES on the power system.

\subsection{Case Study 1}

In this case study, the SMIB work in base case scenario. The SMIB system presented as ninth-order model including exciter and governor. While CES and SPS represented as a second-order model and fourth-order model. Table 1 illustrates the comparison on eigenvalue electromechanical (EM) mode. It was found that by installing SPS in the system, the eigenvalue trajectories move to left-half plane moderately. It was noticeable that the movement was more significantly when installing with CES. Figure 4 depicts the damping performance EM mode of different scenario. It was shown that the damping was increased significantly when CES was installed on the system. It was investigated that the best damping performance was a system with SPS and CES with damping value was $18 \%$, while the standard was $5 \%$ [31]. 
Table 1. Eigenvalue of EM Mode Under Different Scenario

\begin{tabular}{cccc}
\hline Initial condition & SPS & CES & SPS and CES \\
\hline$-0.2943+9.5328 \mathrm{i}$ & $-0.3722+9.5499 \mathrm{i}$ & $-0.7271+9.6342 \mathrm{i}$ & $-0.8115+9.6539 \mathrm{i}$ \\
\hline
\end{tabular}

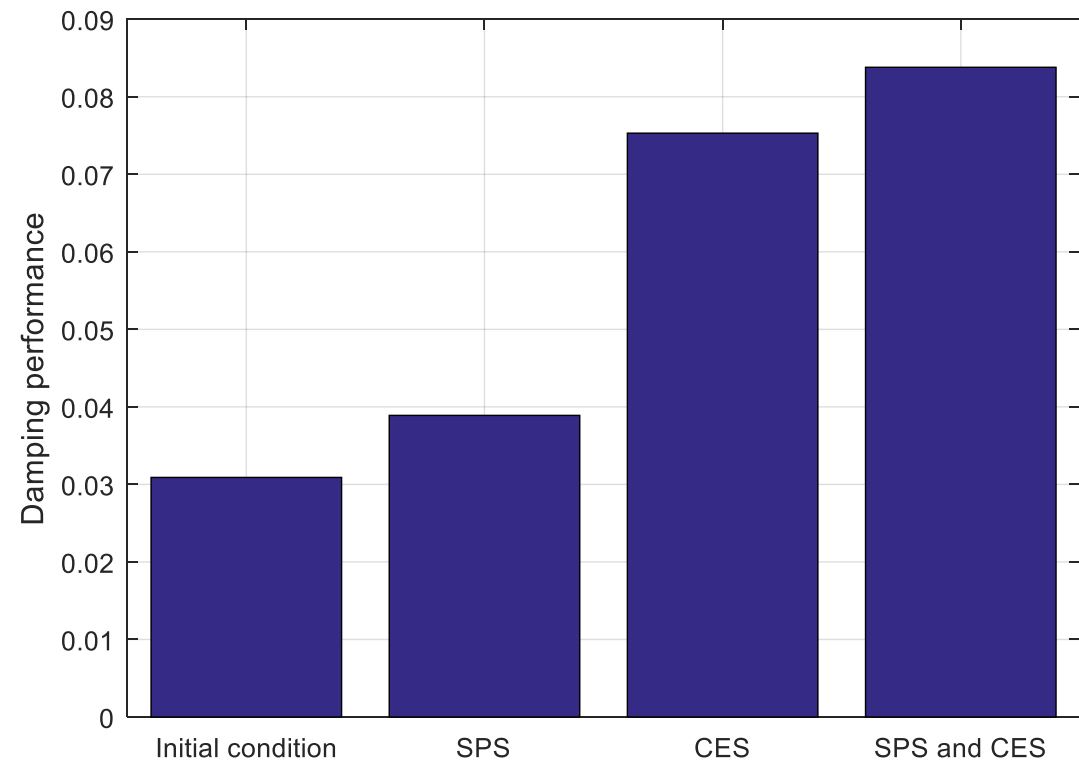

Figure 4. Damping ratio of the cases study

For verify the modal analys analysis, time domain simulation were then conducted. To excite the sensitivity of the eigenvalues, a small disturbance was applied to the system. Rotor speed response of the investigated system was illustrated in Figure 5.

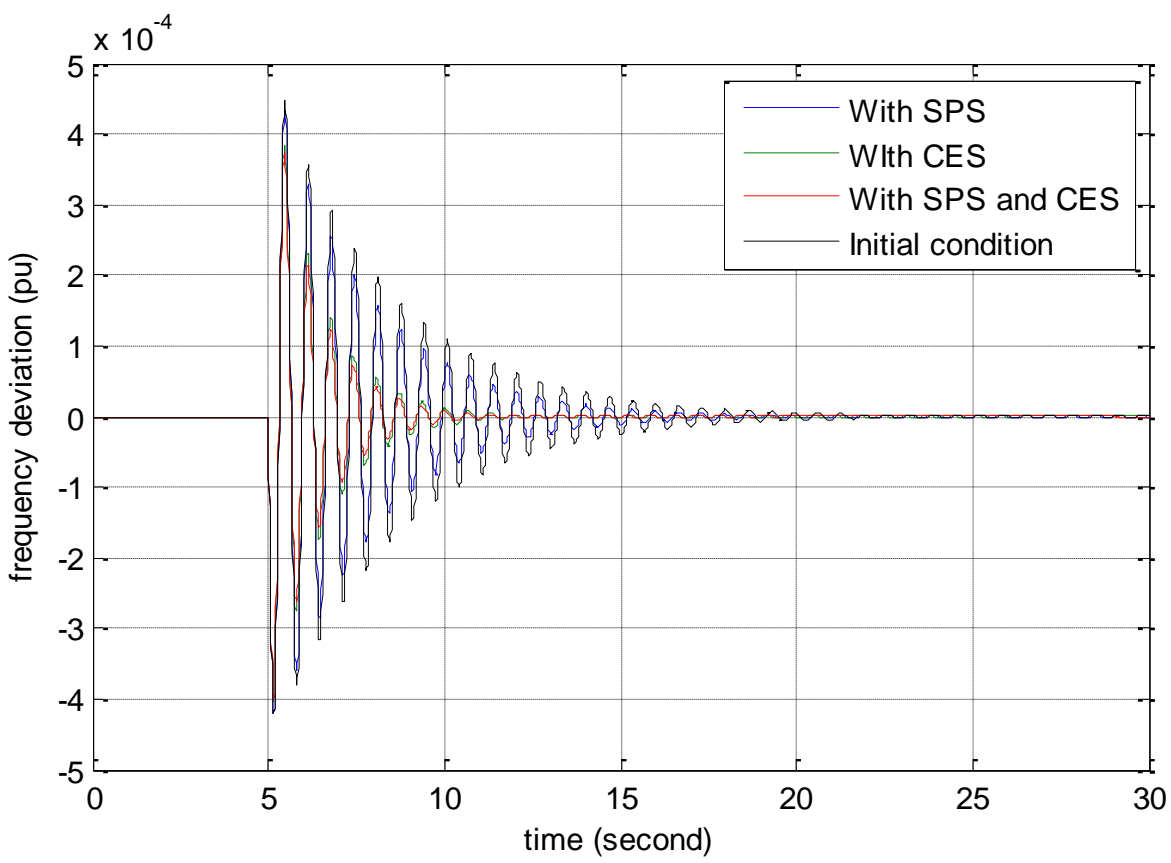

Figure 5. The time domain response of rotor speed under different scenario 
It was noticeable that the initial condition (black lines) has the highest overshoot and the longest settling time. It means that the system without controller was not robust enough to handle the small perturbation. After SPS was installed (blue lines) in the transmission line, the response of the rotor speed was better than the initial condition due to shifted voltage angle of the system. Better response was produced when CES was installed in the load bus. It was found that CES could gave instantaneously active power to the load when there were load changing. Hence this make the burden of the synchronous generator decreased when small load perturbation occurs. The best oscillatory condition was system with SPS and CES indicated by the overshoot and the settling time (smallest and fastest compared to the others scenario). The detailed rotor speed response enhancement shown in Table 2.

Table 2. Detailed Value of Rotor Speed Under Different Scenario

\begin{tabular}{ccccc}
\hline Parameter & Initial condition & SPS & CES & SPS and CES \\
\hline Overshoot $(\mathrm{pu})$ & 0.0004466 & 0.0004353 & 0.0003838 & 0.0003731 \\
Settling Time $(\mathrm{Sec})$ & 22.99 & 17.12 & 10.72 & 8.61 \\
\hline
\end{tabular}

The same pattern was found in the rotor angle oscillatory condition when small pertubation emerges as shown in Figure 6. It was also monitored that system without SPS and CES or the initial condition (black lines) experience the worst oscillation compared to the other scenario. Table 3 illustrates the detailed comparison of rotor angle oscillatory condition. System in initial condition has overshoot -0.02578 pu and settling time more than 20 second. System with SPS has less overshoot than the initial condition which has $-0.02566 \mathrm{pu}$ and settling time 17.76 second. While system with CES has better overshoot and settling time than the initial condition and system with SPS (overshoot is -0.0244 and settling time is 10.35). According to the Paserba [32], the maximum settling time of small signal stability is around 10 second. Hence, only system with SPS and CES was capable to achieved this standard (settling time 7.73 second).

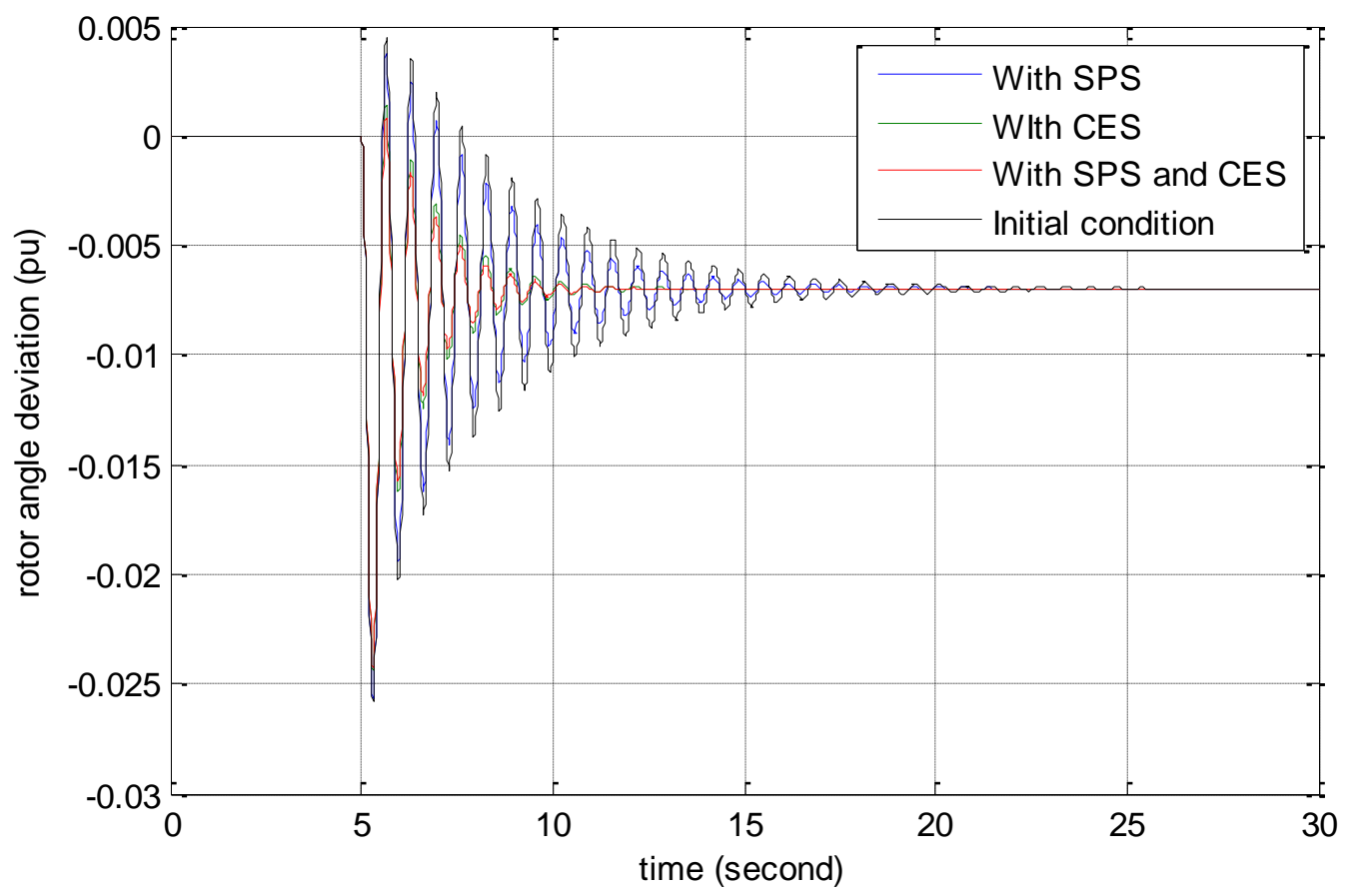

Figure 6. The time domain response of rotor angle under different scenario 
Table 3. Detailed Value of Rotor Angle Time Domain Response

\begin{tabular}{ccccc}
\hline Parameter & Initial condition & SPS & CES & SPS and CES \\
\hline Overshoot $(\mathrm{pu})$ & -0.02578 & -0.02566 & -0.0244 & -0.02429 \\
Settling Time (Sec) & 20.64 & 17.76 & 10.35 & 7.73 \\
\hline
\end{tabular}

\subsection{Case Study 2}

This case study investigated how much load could be increased if the system was installed with SPS and CES. To analyze the impact of increasing load demand on oscillatory condition, damping ratio plot of EM mode was carried out. Figure 7 shows the damping value fluctuation due to increasing the capacity of the load. It was found that by increasing load demand capacity, the damping of the system was deteriorated. It was noticeable found that if the system only used CES alone, the load demand could not be increased more than $55 \%$. If the load was increased more than $55 \%$, it could exceed the minimum standard of damping ratio $(5 \%)$, and it may lead to the unstable condition. It was also noticeable that by combining SPS and CES, the load demand could be increased more than $55 \%$. Hence, by installing SPS and CES, it could stabilize the performance even thought there was increasing load demand on the system.

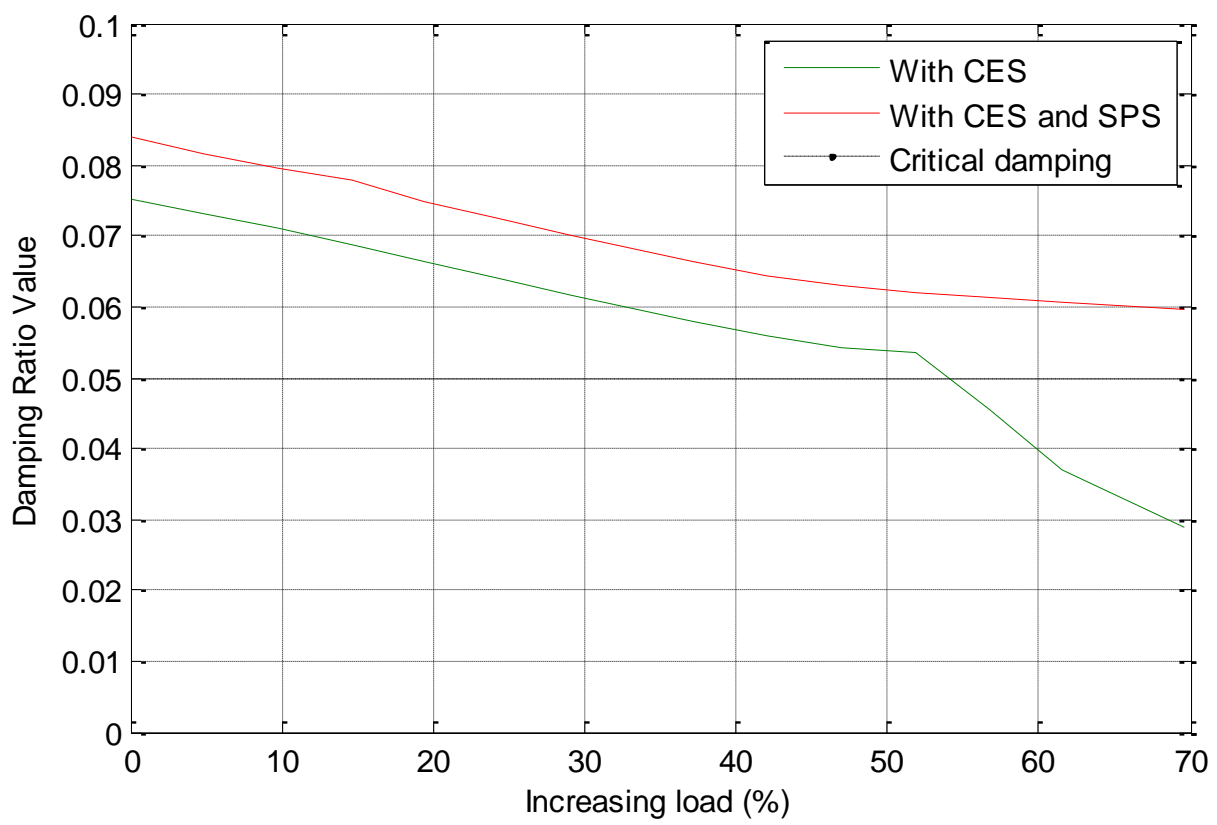

Figure 7. Damping ratio plot due to increasing load demand

\section{Conclusion}

This paper proposed a method to mitigate oscillatory condition on power system by using FACTS devices called solid phase shifter (SPS) and energy storage devices called capacitor energy storage (CES). From the simulation result, it was found that by installing SPS and CES to SMIB, the damping performamce of the system was increased significantly. It was noticeable that SPS and CES could mitigate the oscillatory condition of power system indicated by small overshoot and fastest settling time. It was also found that by installing SPS and CES, the load demand of the system could be increased. Further research is required to be conducted by using larger case study such as two area power system, nine-bus 3 machine power system and New England power system. Furthermore, to enhance the performance of SPS and CES, optimization method based on metaheuristic algorithm can be used to tune SPS and CES parameter. 


\section{References}

[1] M Klein, G Rogers, P Kundur. A fundamental study of inter-area oscillations in power systems IEEE Transactions on Power Systems. 1991; 6: 914-921.

[2] G Rogers. Power system oscillations. Springer Science \& Business Media. 2012.

[3] A Krismanto, N Mithulananthan, KY Lee. Comprehensive Modelling and Small Signal Stability Analysis of RES-based Microgrid. IFAC-PapersOnLine, 2015; 48: 282-287.

[4] L Xu. Coordinated control of SVC and PSS for transient stability enhancement of multi-machine power system. Indonesian Journal of Electrical Engineering and Computer Science, 2012; 11: 10541062.

[5] AB Muljono, IM Ginarsa, IMA Nrartha. Dynamic Stability Improvement of Multimachine Power Systems using ANFIS-based Power System Stabilizer. TELKOMNIKA (Telecommunication Computing Electronics and Control). 2015; 13: 1170-1178.

[6] P Soni, A Saxena, V Gupta. A Minimax Polynomial Approximation Objective Function Approach for Optimal Design of Power System Stabilizer by Embedding Particle Swarm Optimization. TELKOMNIKA Indonesian Journal of Electrical Engineering. 2015; 14: 191-198.

[7] M Sulaiman, HM Hussein, R Omar, Z Salleh. Dynamic Stability Analysis of Generator with Power System Stabilizers Using Matlab Simulink. Indonesian Journal of Electrical Engineering and Computer Science. 2016; 2: 501-509.

[8] T Kerdphol, K Fuji, Y Mitani, M Watanabe, Y Qudaih. Optimization of a battery energy storage system using particle swarm optimization for stand-alone microgrids International Journal of Electrical Power \& Energy Systems. 2016; 81: 32-39.

[9] R Shankar, K Chatterjee, R Bhushan. Impact of energy storage system on load frequency control for diverse sources of interconnected power system in deregulated power environment. International Journal of Electrical Power \& Energy Systems. 2016; 79: 11-26.

[10] D Lastomo, Atmiasri, H Setiadi. Small Signal Stability Enhancement of Hybrid Power System using RFB Tune with Craziness Particle Swarm Optimization. 2017 3nd International Conference on Science in Information Technology (ICSITech). Bandung: Indonesia. 2017.

[11] M Taufik, D Lastomo, H Setiadi. Small-Disturbance Angle Stability Enhancement using Intelligent Redox Flow Batteries. 2017 4th International Conference on Electrical Engineering, Computer Science and Informatics (EECSI 2017). Yogyakarta: Indonesia. 2017.

[12] H Setiadi, AU Krismanto, N Mithulananthan. Enabling BES in Large PV Plant for Stability Enhancement on Power Systems with High RES. 2017 IEEE Innovative Smart Grid TechnologiesAsia (ISGT-Asia). Auckland: New Zealand. 2017.

[13] K Sudha, RV Santhi. Load frequency control of an interconnected reheat thermal system using type-2 fuzzy system including SMES units. International Journal of Electrical Power \& Energy Systems. 2012; 43: 1383-1392.

[14] M Ponnusamy, B Banakara, SS Dash, M Veerasamy. Design of integral controller for Load Frequency Control of Static Synchronous Series Compensator and Capacitive Energy Source based multi area system consisting of diverse sources of generation employing Imperialistic Competition Algorithm. International Journal of Electrical Power \& Energy Systems. 2015; 73: 863-871.

[15] D Lastomo, H Setiadi, M Faisal, A Ashfahani, G Bangga, G Hutomo, et al. The Effects of Energy Storage on Small Signal Stability of a Power System. 2017 International Seminar on Technology and Its Application (ISITIA). Surabaya: Indonesia. 2017.

[16] D Lastomo, H Setiadi, MR Djalal. Optimization of SMES and TCSC using particle swarm optimization for oscillation mitigation in a multi machines power system. Journal of Mechatronics, Electrical Power, and Vehicular Technology. 2017; 8: 11-21.

[17] K Prasertwong, N Mithulananthan, D Thakur. Understanding low-frequency oscillation in power systems. International Journal of Electrical Engineering Education. 2010; 47: 248-262.

[18] H Setiadi, KO Jones. Power System Design using Firefly Algorithm for Dynamic Stability Enhancement. Indonesian Journal of Electrical Engineering and Computer Science. 2016; 1: 446455.

[19] H Setiadi, N Mithulananthan, MJ Hossain. Impact of Battery Energy Storage Systems on Electromechanical Oscillations in Power Systems. 2017 IEEE Power and Energy General Meeting. Chicago: USA. 2017.

[20] RJ Abraham, D Das, A Patra. Effect of capacitive energy storage on automatic generation control. 2005 International Power Engineering Conference. 2005: 1070-1074.

[21] RJ Abraham, D Das, A Patra. Automatic generation control of an interconnected power system with capacitive energy storage. International Journal of Electrical Power and Energy Systems Engineering. 2010; 3: 351-356.

[22] NV Kumar, MMT Ansari. A new design of dual mode Type-II fuzzy logic load frequency controller for interconnected power systems with parallel AC-DC tie-lines and capacitor energy storage unit. International Journal of Electrical Power \& Energy Systems. 2016; 82: 579-598.

TELKOMNIKA Vol. 15, No. 4, December 2017: 1601 - 1609 
[23] D Lastomo, Widodo, H Setiadi, MR Djalal. Enabling PID and SSSC for Load Frequency Control using Particle Swarm Optimization. 2017 3nd International Conference on Science in Information Technology (ICSITech). 2017.

[24] M Abido. Simulated annealing based approach to PSS and FACTS based stabilizer tuning. International Journal of Electrical Power \& Energy Systems. 2000; 22: 247-258.

[25] R Shah, N Mithulananthan, AS Yome, KY Lee. Impact of large-scale PV penetration on power system oscillatory stability. IEEE PES General Meeting. 2010: 1-7.

[26] H Setiadi, AU Krismanto, N Mithulananthan. Influence of BES System on Local and Inter-Area Oscillation of Power System with High Penetration of PV Plants. 2017 IEEE International Conference on Applied System Innovation. Sapporo: Japan. 2017.

[27] AU Krismanto, M Nadarajah, O Krause. Influence of renewable energy based microgrid on low frequency oscillation of power systems. 2015 IEEE PES Asia-Pacific Power and Energy Engineering Conference (APPEEC). 2015: 1-5.

[28] H Setiadi, I Robandi, T Yuwono. Penalaan Parameter Superconducting Magnetic Energy Storage (SMES) menggunakan Firefly Algorithm (FA) pada Sistem Tenaga Listrik Multimesin. Jurnal Teknik ITS. 2014; 3: B12-B17.

[29] P Kundur, NJ Balu, MG Lauby. Power system stability and control. McGraw-hill: New York. 1994.

[30] AU Krismanto, N Mithulananthan, O Krause. Microgrid impact on low frequency oscillation and resonance in power system. 2016 IEEE Innovative Smart Grid Technologies-Asia (ISGT-Asia). 2016: 424-429.

[31] LL Grigsby. Power system stability and control. CRC press. 2012.

[32] J Paserba. Analysis and control of power system oscillation. CIGRE special publication. 1996; 38. 